\author{
О.И. Глазунова \\ Санкт-Петербургский государственный университет \\ (Санкт-Петербург, Россия) \\ o.i.glazunova@mail.ru
}

\title{
АЛГОРИТМИЧЕСКИЕ МОДЕЛИ КАК ПРИНЦИП ОПИСАНИЯ ЯЗЫКА И ПОСТРОЕНИЯ РЕЧИ
}

Язык относится к сфере познания внутреннего мира человека: его изучение традиционно проходило в изоляции от естественно-научных дисциплин, описывающих законы строения и развития мира внешнего. Однако язык обладает и материальной формой, которая должна подчиняться единым для природных систем правилам: включать динамику развития событий, существовать на основе образующих цикл алгоритмов и создаваться для выполнения определенных задач.

Алгоритмический принцип осуществления структурно-системных преобразований присутствует на всех языковых уровнях как система решающих правил, которые в случае их выявления помогают понять закономерности и природу языковых процессов. (Например, разницу в употреблении предлогов om и из при выражении причины (остановиться от страха (из вежливости)), противительных союзов $a$ и но, форм именительного и родительного падежей определительного слова при существительном после числительных два, mpu, четыре (три моих двоюродных брата - три мои двоюродные сестры); необходимость использования союза чтобы в конструкциях со значением цели и т. д.)

Статья посвящена поискам факторов внутреннего развития языка и объективным показателям, которые обусловливают принципы сочетаемости языковых единиц в речи. В настоящее время лингвистика не может ограничиваться описательными методами исследований; необходимо переходить к поиску закономерностей, которые определяют функционирование языка как системного образования, состоящего из элементов разных уровней, пребывающих в постоянном взаимодействии не только друг с другом, но и с окружающей действительностью.

Ключевые слова: алгоритмические модели, продуктивная грамматика, системность языка, сочетаемость языковых единиц в речи. 


\section{1. Введение}

Способность к отображению мыслей, чувств, эмоций делает язык одним из основных инструментов познания окружающей человека действительности. И хотя внутренний мир относится к нематериальным сущностям, он базируются на обладающих формой графических знаках, фонетических, морфологических, лексических и синтаксических единицах, которые, как любая другая материя, должны подчиняться законам природы.

Именно это мы наблюдаем в языке. Расширение звукового, лексического и синтаксического состава языка приводит к качественному усложнению выражаемой с их помощи информации, предопределяя поступательное ее развитие в рамках закона перехода количественных изменений в качественные. Базирующиеся на противопоставлении принципы сочетаемости в языке (тоновая основа гласного дополняется шумовой природой согласных звуков, субъект с предметным значением образует связь с предикатом со значением признака) подчиняются закону единства и борьбы противоположностей. Принципы организации языковых единиц разных уровней, когда «ядерный» компонент (гласный звук, ударный слог, корневая морфема, главное слово в составе словосочетания, субъект и предикат) уравновешивается периферией, подчиняются закону иерархической упорядоченности систем и т.д. Как любая «живая» система язык переживает определенные стадии развития, в ходе которых его структура проходит многочисленные преобразования (мутации), ее формирование происходит в том виде, который лучше всего отвечает целевому назначению - выражению содержания и выполнению коммуникативной функции.

Процессы, которые происходят в языке, ничем не отличаются от любых других природных процессов, где все взаимообусловлено и алгоритмически выверено таким образом, чтобы обеспечить поступательное развитие системы. Естественный отбор как основной механизм эволюции в природной среде основан на функции приспособленности; его смысл состоит в достижении результата, обеспечивающего организму оптимальное взаимодействие частей в составе целого. То же самое происходит в языке: позиционные изменения согласных и гласных звуков на письме и в речи, использование различных грамматических форм и лексических средств в одних и тех же структурах с частичным или полным изменением содержания обусловлено переходом от структурных языковых компонентов к их системной организации в соответствии с едиными, обусловленными природой, алгоритмами преобразования и развития.

В РКИ данное направление изучения языковых структур получило название функционально-коммуникативной грамматики. Цель его состояла в том, чтобы «представить закономерности и алгоритмы построения речи в условиях конкретного дискурса, для чего нужно, с одной стороны, понять динамику языка в синхронии, то есть понять, как работает язык в процессе пользования им; что происходит с единицами языка (и каковы они - эти единицы) при речепостроении, какие факторы и как действуют на построение речи, а с другой - знать все нюансы словоизменения и словообразования» [Всеволодова 2003: 60]. 
Алгоритм подразумевает функционально-обусловленное действие, в нашем случае - выбор из имеющихся вариантов, который говорящий делает на основе объективных, поддающихся проверке критериев в процессе построения речи. Заложенные в языке принципы преобразования материи в информационное сообщение способствуют тому, что языковые структуры, предназначенные для описания положения дел в действительности, выполняют ещё одну функцию - предоставляют в распоряжение человека методологическую базу, которая, с одной стороны, предопределяет стратегию познания окружающей среды, а с другой — развивает его мыслительные и познавательные способности. Вместе с тем, в отличие от природной среды, язык представляет собой результат работы сознания, в котором цель не только изначально заложена, но и обладает специальными средствами выражения на лексическом и синтаксическом уровне.

Алгоритмический принцип осуществления структурно-системных преобразований присутствует на всех языковых уровнях как система решающих правил, которые в случае их выявления помогают понять закономерности и природу языковых процессов. В основе выбора нормативного варианта могут лежать формальные показатели. Например, с частицей давай глаголы несовершенного вида употребляются в форме инфинитива (давай читать), а глаголы совершенного вида - в форме 1-го лица мн. числа (давай почитаем); при наличии определяемого слова родительный партитивный не употребляется: кусок cblpa/cыpy - кусок российского cырa; при обозначении количества определяемое слово стоит в форме родительного падежа при существительных мужского рода и в форме именительного падежа при существительных женского рода (три моих двоюродных (Р.п.) брата — три мои двоюродные (Им.п.) сестры); союз чтобы употребляется в обязательном порядке при наличии дополнительного объекта (Взял книгу почитать. - Взял книгу, чтобь почитать её сыну) и т. д.

Гораздо сложнее делать выбор, который определяется смысловыми показателями. Например, употребление краткой или полной формы прилагательного (Он болен. - Он больной) обусловлено заложенным в содержании временным или постоянным значением признака; сложная превосходная степень прилагательного передает абсолютное значение (самый великий поэт), простая превосходная степень значение относительное (величайший поэт - один из самых великих). В целевых конструкциях с глаголами движения везти, вести, нести в сочетании с прямыми объектами использование союза чтобы указывает на то, что действие инфинитива относится к субъекту: Родители отвезли детей к бабушке, чтобы отдохнуть (чтобы родители отдохнули); при его отсутствии действие инфинитива относится к объекту: Родители отвезли детей к бабуике отдохнуть (чтобы дети отдохнули) [Глазунова 2017б: 87]. Во всех этих случаях выбор нужной конструкции определяется отправителем речи и соотносится с закрепленным за ней содержанием. Если носители языка делают выбор автоматически, то для иностранцев и компьютерных программ должна быть разработана система специальных алгоритмических правил.

Стоит отметить, что традиционная лингвистика недостаточно внимания обращает на такого рода проблемы. Например, большое количество работ отечественных 
исследователей посвящено средствам выражения причины в простом предложении. Авторы подробно разбирают особенности употребления предложно-падежных форм со значением причины, исходя из их рецептивных особенностей, в то время как вопросы, связанные с правилами использования близких по значению предлогов в рамках продуктивной грамматики, не получают должного освещения.

\section{2. Предлоги от и из со значением причины в простом предложении}

Л.Н. Иорданская и И.А. Мельчук описывают семантику предлога от следующим образом: предлог служит 1) «для выражения непосредственной причины, которая своим воздействием вызывает некоторую реакцию (У Петра от страха лоб покрылся испариной)»; 2) «для выражения первоначальной причины (Все комплекcы Петра - от страха)» [Иорданская, Мельчук 1996: 199]. Предлог из, согласно авторам статьи, служит «для выражения мотива или побудительной силы (психическое состояние или свойство) контролируемого действия (Петр не критикует начальство из каких-то тайных соображений)» [Иорданская, Мельчук 1996: 200].

К сожалению, указанные авторами критерии непосредственности, первоначальности и побудительности, которые следует учитывать при употреблении предлогов от и из с причинным значением, не всегда позволяют выбрать правильный вариант, особенно в сочетании с существительными, обозначающими чувства.

Например, в предложении Все комплексы Петра - от страха, приведенном авторами в качестве примера «первоначальной причины», страх в равной степени может рассматриваться и как побудительная сила, которая, согласно их определению, должна сопровождаться употреблением предлога из; однако использование из в данном предложении не является нормативным. Опираясь на предложенные авторами принципы разграничения, невозможно объяснить причину употребления предлога от или из и в таких словосочетаниях, как остановился от страха - остановился из вежливости; потерял голову от любви - работал из любви к искусству. А ведь в каждом из этих примеров предлог эксплицирует значение, которое не может быть выражено другим способом. Отсюда следует, что без установления четких критериев разграничения синонимичных средств выражения в контекстах, где они не могут заменять друг друга, невозможно выявить разницу между ними.

Действия, которые соотносятся с существительными с предлогами от и из, можно разделить на две группы в соответствии с тем, какой причиной они обусловлены: внешним воздействием на субъекта или исключительно его внутренним состоянием [Глазунова 2017a: 22]. Предлог от употребляется с существительными, которые выражают ответную реакцию на воздействие извне (Om $\mathrm{cmpaxa} \mathrm{он}$ не мог говорить - что-то в его окружении сильно напугало его); из - с существительными, которые обозначают чувство, заложенное или зародившееся в субъекте и направленное вовне (Он не ответил из страха быть наказанным ).

В первом примере (с предлогом om) страх возник в результате внешнего воздействия на субъекта некой силы (причины), которая и вызвала состояние онемения. Во втором примере (с предлогом из) страх обусловлен внутренними 
причинами - личностными характеристиками субъекта (его трусостью); он исходит изнутри и направлен вовне. Непосредственного воздействия на субъекта во втором случае не было; состояние, которое привело к решению промолчать, результат свойственной человеку душевной слабости.

Критерий неконтролируемости/контролируемости действия, который Л. Н. Иорданская и И.А. Мельчук кладут в основу употребления предлогов от и из [Иорданская, Мельчук 1996: 184], в данном случае работает лишь частично, потому что, например, в словосочетаниях помог из жалости, убил из ревности, замел из любопытства предложные лексемы нельзя отнести к «побудительной силе (психическому состоянию или свойству) контролируемого действия», как нам предлагают сделать авторы статьи. Если человек бросается на помощь, рискуя жизнью, совершает что-то под воздействием ревности или любопытства, его действия носят спонтанный характер и их вряд ли можно рассматривать как контролируемые. Следовательно, нужен другой подход и другой принцип разграничения.

С нашей точки зрения, значения форм помог из жалости, убил из ревности, зашел из любопытства соответствуют критерию «направленности причины изнутри вовне» (от субъекта - во внешний мир). Склонность к жалости или ревности, любопытство - это внутренние причины, которые вызвали определенные действия: помог, убил, зашел. В то время как примеры с предлогом от: страдал от комплексов, мучился от ревности, покраснел от стыда, вздрогнул от неожиданности, соответствуют другому критерию - «направленности причины извне», из внешнего мира (возможно, из оценки себя или своего поведения во внешнем мире) на субъекта или на объект.

Сравните: страдал от комплексов (комплексы - причина, воздействующая на субъекта состояния) - страдал из вредности (вредность - причина, которая оказывает воздействие на окружающий мир). Неслучайно в словосочетаниях, выражающих физические изменения под влиянием окружающей среды: побелел от холода, ослаб от голода, оглох от крика, потемнел от времени, употребить предлог из невозможно. Подход, при котором причина рассматривается как фактор направленного воздействия, полностью соответствует семантике предлогов от и из.

Любое действие причинно-обусловлено, но эти причины имеют разную природу: они могут быть внутренними, исходящими от человека (т. е. определяющимися его личностными особенностями) и направленными вовне, или внешними - представляющими собой следствие воздействия на человека внешних факторов.

Значения глаголов в словосочетаниях с предлогами от и из лишь в некоторых случаях определяют выбор предлога (Ср.: остановился от страха - остановился из вежливости). Основополагающим в приведенных выше примерах является направленность обусловливающего причину фактора - от субъекта или на субъекта (на объект). Вежливость (остановился из вежливости) - это то, что было заложено в человека; она направлена вовне, в отличие от чувства страха (остановился oт страха), возникшего под воздействием внешних факторов.

Неслучайно существительные, семантика которых ограничивается внутренним миром человека (например, счастье, радость, печаль, грусть), с предлогом из со 
значением причины не употребляются. Другие существительные (обида, досада, беспечность), значение которых может соотноситься с побудительными намерениями, используются с предлогом из крайне редко; носителями языка такие формы обычно воспринимаются как разговорные: «Утверждают, что из обиды и мести они расстреляли своих военных советников»; «Посему недопустимо совершать сей шаг необдуманно, из беспечности либо ради забавы, но лишь по зрелому размышлению» (примеры из Интернета).

Как любое системное образование язык подчиняется логике развития окружающего мира, следовательно, все в нем должно быть предопределено и логически выверено. Задача лингвистов заключается не столько в описании того, что мы имеем, сколько в выявлении причинно-следственной обусловленности существования и использования тех или иных языковых единиц в языке и речи.

\section{1. Союзы $а$ и но в сложносочиненных конструкциях}

Отношения противопоставления, определяющие варианты сосуществования ситуаций в пространстве и времени, лежат в основе использования в языке противительных союзов $a$ и но, которые «наряду с союзом $u$, формируют ядро системы русских сочинительных союзов» [Урысон 2004: 65]. В отличие от $u$, союзы $a$ и но употребляются для выражения противопоставления событий, которые в целом или по ряду признаков соотносятся друг с другом. При этом, несмотря на общность выражаемого ими значения, союзы $a$ и но не всегда могут заменять друг друга в предложении.

Самую большую сложность для иностранцев, которые изучают русский язык, а также для переводчиков, работающих с русскими текстами, представляет союз a. Он не имеет аналогов во многих других языках и, по мнению исследователей, «с большим трудом поддается семантической экспликации» [Урысон 2004: 64]. Действительно, стоит отметить, что значения, которые союз $а$ выражает в составе предложения, в отечественной лингвистической литературе описываются по-разному и с самых разных позиций.

Анна А. Зализняк и И.Микаэлян вслед за А.Вежбицкой [Wierzbicka 1992] отмечают, что «союз $а$ заключает в себе одну из ключевых идей русской языковой картины мира, а именно, идею непредсказуемости мира» [Зализняк, Микаэлян 2005]. Вслед за В.3. Санниковым, назвавшим но союзом «ненормального следствия» [Санников 1989], Е. В. Урысон предложила использовать то же самое наименование по отношению к союзу $a-\ll a$ ненормального следствия» [Урысон 2005].

По мнению Е.В. Падучевой, семантика союза $a$ определяется «эгоцентричностью (ориентированностью на субъекта сознания)» [Падучева 1997: 37], при этом «в роли субъекта сознания, предполагаемого семантикой этого союза, выступает говорящий - или, в повествовательном тексте, его обычные заместители» [Падучева 1997: 47]. Исходя из этого, отличие союза но (вторичного эгоцентрика, по определению Падучевой) от союза $a$ (первичного эгоцентрика) состоит в том, что выражаемое им значение отражает точку зрения не субъекта сознания, а лица, упомянутого в предложении. 
Если данный принцип работает, то лишь частично. Например, и в предложении Зарплату повысили, а денег по-прежнему не хватает, и в предложении Зарплату повысили, но денег по-прежнему не хватает определить, кто является субъектом оценки: отправитель речи (субъект сознания) или лицо, которому эту зарплату повысили (т.е. объект речи), крайне сложно. Во многих предложениях с противительными союзами не содержится никаких объективных показателей, позволяющих сделать на этот счет однозначный вывод.

Аналогичную ситуацию мы наблюдаем и при других толкованиях данных союзов. Мало что дают и существующие на сегодняшний момент классификации.

В.В. Виноградов выявляет четыре значения союза $a$ : противительное (Мужчина, а плачет; Они проснулись, а мы спать собираемся), присоединительное (Встала перед глазами изба голодная, а в избе голодной мать хворая лежит), противительно-перечислительное ( $A$ где же другие товарищи? А Данилов?), присоединительно-усилительное ( $А$ дура-то врет, врет, да и правду соврет) [Виноградов 2001: 583-584].

В более распространенной классификации союзов, приведенной в работе Г.Е. Крейдлина и Е.В. Падучевой, выделяется три значения союза $a$ : сопоставление (Отеи был летчик, а сын избрал ученую карьеру), несоответствие (Дело к весне, а мороз все жестче), присоединительное (3а деревней было поле, а за полем начинался лес) [Крейдлин, Падучева 1974].

Очевидно, что, за исключением присоединительного, остальные значения, которые приписываются союзу $а$ в работах Г. Е. Крейдлина, Е.В. Падучевой и В. В. Виноградова, не совпадают, а потому заключение, к которому приходят В. Ю. Апресян и О.Е. Пекелис на сайте «Проекта корпусного описания русской грамматики», вполне оправданно: «По поводу семантики союза А существует множество работ, однако до сих пор не сформулировано однозначных правил его употребления» [Апресян, Пекелис 2012].

Чтобы разобраться в этом вопросе, обратимся к определению прилагательного «противительный», обозначающего разряд, в который входят союзы $a$ и но. «ПРОТИВИТЕЛЬНЫЙ, -ая, -ое. В грамматике: выражающий отношения противопоставления» [Ожегов, Шведова 1999: 624] (подчеркнуто мной - О.Г.). Существительное «противопоставление», в свою очередь, образуется от глагола «противопоставлять», значение которого выражается следующим образом: «ПРОТИВОПОСТАВЛЯТЬ, несов. (сов. противопоставить), кого-что кому-чему. Сопоставлять (сопоставить) кого-, что-л. с кем-, чем-Л., указывать (указать) несходство, противоположность признаков одного и другого, давая рядом что-л. несходное)» [Толковый словарь русских глаголов 1999: 324] (подчеркнуто мной - О.Г.).

В определении глагола «противопоставлять» указываются два значения, которые определяют действие: 1) несходство и 2) противоположность. Именно они соответствуют значениям союзов $a$ и но. Очевидно, что между этими понятиями существует принципиальная разница: несходство соотносится с существительными «непохожесть, неодинаковость» [Александрова 2001: 261], а противоположный трактуется как «совершенно несходный, противоречащий другому» [Ожегов, Шведова 1999: 624]. 


\section{2. Несоответствие Vs Противоречие: принцип разграничения союзов $а$ и но в русском языке}

Итак, противопоставление в русском языке подразумевает два варианта взаимодействия ситуаций в рамках сложного предложения: 1) на основе несходства входящих в их состав и соотносящихся между собой однотипных элементов (субъектов, объектов, действий, признаков, обстоятельств); 2) на основе противоречия между ними. Эти два отличных друг от друга варианта восприятия окружающей действительности находят отражение в языковых структурах, в частности в правилах употребления союзов $a$ и но в составе сложносочиненного предложения.

Чтобы понять разницу в употреблении союзов, из примеров, представленных в работах В.В. Виноградова, В.З. Санникова, Г.Е. Крейдлина, Е.В. Падучевой, Е.В. Урысон, мы выбрали те, в которых союз $a$ не может быть заменен союзом но. При этом предложения с присоединительным и противительно-перечислительным значениями типа За деревней было поле, а за полем начинался лес; $A$ где же другие товарищи? А Данилов? нами не рассматривались на том основании, что вопросов по употреблению в них союза не возникает.

Все выбранные примеры указали на то, что союз $a$ в нейтральном стиле речи употребляется при наличии несходства между двумя описываемыми ситуациями: Они проснулись, а мы спать собираемся; Он сидел в тюрьме, а годы или; Вы аристократ, а я демократка; Он днем спит, а ночью работает; Петров болен, а Сидоров в командировке. При этом несходство может проявляться при описании нескольких субъектов (Он шел пешком, а его брат ехал на велосипеде) или одного и того же (Он днем спит, а ночью работает).

В отличие от союза $a$, союз но в сложном предложении используется для выражения противоречия между описываемыми ситуациями или входящими в их состав частями: День был дождливый, но Коля не взял зонт; Его фамилия Вернер, но он русский; Он звал, но я не поехала; Дико и странно может показаться все это, но я пишу одну правду; Иван развелся с Лидией, но на Кате так и не женился. В такого рода конструкциях союз но объединяет две части, в которых одна исключает другую или оценивается как несовместимая с ней в силу антонимичности входящих в их состав компонентов. Информация, представленная во второй части сложного предложения: не взял зонт, он русский, я не поехала, я пишу одну правду, на Кате так и не женился, не соответствует тому, что изложено в первой части, - так не должно было произойти, потому что случившееся противоречит традиционным взглядам и нормам поведения в обществе ${ }^{1}$.

Различия в употреблении союзов $а$ и но имеют системный характер. С помощью языка человек структурирует и оценивает окружающую его действительность. Чтобы обозначить заложенные в природе или возникающие в процессе развития событий противоречия, необходимо использовать инструмент, который позволяет описывать систему в виде причинно-следственных связей. Для этого можно использовать

\footnotetext{
1 О разнице в употреблении союзов $а$ и но см. [Глазунова 2017: 270б].
} 
не только конструкции с союзом но, но и с союзом хотя со значением уступки ${ }^{2}$ День был дождливый (солнечный), но Коля не взял зонт (взял зонт) - Хотя день был дождливый (солнечный), Коля не взял зонт (взял зонт). При этом трансформировать таким же образом предложения, в которых используется только союз $a$, невозможно, потому что союз $а$ соединяет ситуации, не связанные друг с другом причинно-следственными отношениями (Он шел пешком, а его брат ехал на велосипеде).

Вместе с тем в большинстве сложносочиненных конструкций союз но может быть заменен союзом $a$, на что неоднократно указывали исследователи: День был дождливый, но (а) Коля не взял зонт; Вылграл Чемпионат Европь, но (а) на Олимпиаде не вошел в шестерку сильнейших. В.З. Санников разграничивает значение союзов в этом случае следующим образом: «Союз но указывает на зависимость компонентов Р и Q (Коля знал, что погода дождливая, и все-таки не взял зонт); союз $а$ описывает события как независимые (возможно, когда Коля собирался, дождя еще не было)» [Санников 1989: 170-171].

И хотя Е.В. Урысон считает, что «В. З. Санников дал точную экспликацию различий между этими фразами» [Урысон 2005], с этим вряд ли можно согласиться, потому что событие, описываемое конструкцией с союзом а (а Коля не взял зонт), могло попасть в поле зрения отправителя речи только при условии дождливого дня. Эти две ситуации причинно-обусловлены, а потому рассматривать их как независимые невозможно.

C нашей точки зрения, варианты с союзом $a$ (при возможном употреблении но в данной позиции) указывают на экспрессивный характер высказывания [Глазунова 2017б: 270]. Ср.: Молодой, а опьтный (Удивительно!); Мужчина, а плачет; Он шел пешком, а добрался быстрее нас (Надо же!); Его имя Вернер, а он русский (Бывает же такое!).

Таким образом, союз $a$ в русском языке предназначен для выражения несходства при сопоставлении ситуаций, параллельно или последовательно развивающихся в пространстве и времени, союз но служит для констатации заложенного в них противоречия, т. е. имеет причинно-следственную основу. Замена союза но союзом $a$ в такого рода конструкциях приводит в действие стилистические механизмы, добавляя значение экспрессивности в оценке и передаче отправителем речи сложившихся противоречий.

\section{4. Выводы}

Системный подход к решению задач позволил многое понять в теории эволюции, в исследовании генетического кода, в синергетике, а также сформулировать методологические алгоритмы объяснения принципов формирования, развития

${ }^{2}$ В ряде случаев даже сложносочиненное предложение с союзом $u$ может указывать на противоречие. Как остроумно заметил американский математик Стивен Клини, «хотя в исчислении высказываний A\&B равносильно B\&A, фразы “У Джейн родился ребёнок, и она вышла замуж" и “Джейн вышла замуж, и у неё родился ребёнок” будут пониматься знакомыми Джейн по-разному» [Клини 1973: 82]. 
и взаимодействия объектов и процессов, составляющих функционально обусловленное целое.

Тот же самый подход «работает» и в языке, который является системным образованием, выполняющим не только семиотическую, но и коммуникативную, когнитивную, номинативную и аккумулятивную функции. Все в языке предопределено и основано на объективных показателях, которые могут быть выявлены через систему решающих правил (алгоритмов), направленных на поиск закономерностей в формировании и развитии языковых структур, а также в характере их взаимодействия в рамках выполнения свойственных языку функций.

Данное направление в лингвистике является весьма перспективным и в теоретическом, и в практическом отношении. Очевидно, что сегодня от описания разного рода лексических, грамматических, синтаксических форм и конструкций надо переходить к объяснению того, в силу чего они возникли и на основе каких принципов взаимодействуют друг с другом, - т. е. к поискам факторов внутреннего развития языка.

\section{Литература}

Александрова 3. Е. Словарь синонимов русского языка. Практический справочник. Изд. 11-е, перераб. и доп. М.: Русский язык, 2001. 568 с.

Апресян В.Ю., Пекелис О.Е. Сочинительные союзы. Материалы для проекта корпусного описания русской грамматики (http://rusgram.ru). На правах рукописи. M., 2012 [Электронный ресурс]. URL: http://test.rusgram.ru//Сочинительные_союзы (дата обращения: 02.10.2019).

Виноградов В.В. Русский язык (Грамматическое учение о слове) / под ред. Г. А. Золотовой. Изд. 4-ое. М.: Русский язык, 2001. 720 с.

Всеволодова М. В. Функциональная прикладная грамматика русского языка как основа для создания учебников и учебных пособий по русскому языку как иностранному // Сопоставительная филология и полилингвизм: Сборник научных трудов / под ред. А. А. Аминовой, Н. А. Андрамоновой. Казань, 2003. С. 59-66.

Глазунова О.И. Грамматика русского языка в упражнениях и комментариях. В 2 ч. Ч. 1. Морфология. 9-ое изд. СПб.: Златоуст, 2017а. 424 с.

Глазунова О.И. Грамматика русского языка в упражнениях и комментариях. В 2 ч. Ч. 2. Синтаксис. 5-ое изд. СПб.: Златоуст, 2017б. 416 с.

Зализняк Анна А., Микаэлян И. Русский союз а как лингвоспецифичное слово // Компьютерная лингвистика и интеллектуальные технологии. По материалам ежегодной Международной конференции «Диалог». М.: Наука, 2005 [Электронный pecypc]. URL: http://www.dialog-21.ru/media/2439/zalizniak_mikaelian.pdf (дата обращения: 02.10.2019).

Иорданская Л.Н., Мельчук И.А. К семантике русских причинных предлогов (ИЗ-ЗА любви $\sim$ ОТ любви $\sim$ ИЗ любви $\sim *$ С любви $\sim$ ПО любви) // Московский лингвистический журнал. Том 2. М.: РГГУ, 1996. С. 162-211.

Клини С.К. Математическая логика / пер. с англ. Ю.А. Гастева, под ред. Г.Е. Минца. М.: Мир, 1973. 480 с. 
Крейдлин Г.Е., Падучева Е.В. Значение и синтаксические свойства союза $a$ // Научно-техническая информация. Серия 2. Информационные процессы и системы. 1974. №9. С. 31-37.

Ожегов С. И., Шведова Н. Ю. Толковый словарь русского языка. Изд. 4-ое, доп. М.: Азбуковник, 1999. 944 с.

Падучева Е. В. Эгоцентрическая семантика союзов А и $\mathrm{HO} / /$ Славянские сочинительные союзы. М., 1997. С. 36-45.

Санников В.3. Русские сочинительные конструкции: семантика, прагматика, синтаксис. М.: Наука, 1989. 266 с.

Толковый словарь русских глаголов: Идеографическое описание. Английские эквиваленты. Синонимы. Антонимы / под ред. Л.Г. Бабенко. М.: АСТ-ПРЕСС КНИГА, 1999. $698 \mathrm{c}$.

Урысон Е. В. Союзы $а$ и но и фигура говорящего // Вопросы языкознания. 2004. № 6. C. 64-83.

Урысон Е.В. Союз но, или что такое «обманутое ожидание» // Компьютерная лингвистика и интеллектуальные технологии. По материалам ежегодной Международной конференции «Диалог». М.: Наука, 2005 [Электронный ресурс]. URL: http://www.dialog-21.ru/media/2430/urysone.pdf (дата обращения: 02.10.2019).

Wierzbicka A. Semantics, Culture, and Cognition. Universal Human Concepts in Culture-Specific Configurations. N. Y., Oxford: Oxford Univ. Press, 1992. 328 p.

\section{Olga I. Glazunova}

Saint Petersburg State University

(Saint Petersburg, Russia)

o.i.glazunova@mail.ru

\section{ALGORITHMIC MODELS AS A PRINCIPLE OF THE LANGUAGE DESCRIPTION AND THE SPEECH FORMATION}

Language is part of a person's inner life: its study has traditionally taken place in isolation from the natural sciences, which describe the laws of the structure and development of the outer world. However, language also has a material form that should be subject to the same rules, contain within itself event dynamics, exist on the basis of cyclical algorithms, and perform certain tasks.

The algorithmic principle of structural and systemic transformations is present at all levels of language as a system of decision-influencing rules, which, if identified, can help us to understand the existing laws and the nature of language processes, for example: the difference in Russian between the prepositions om and $и з$ expressing reason or cause (остановиться от страха versus из вежливости), the contrasting conjunctions $a$ and $н о$, the nominative or genitive case of determiners in expressions of quantity with the numbers two, three, four (три моих двоюродных брата - три 
мои двоюродные сестры); the requirement to use the conjunction чтобы in subordinate clauses, etc.

This paper studies factors influencing the internal development of language and objective indicators that determine the principles of compatibility of language units in speech. At present, linguistics cannot be limited to descriptive methods of research. It is necessary to move on to the search for patterns that determine the functioning of language as a system whose elements are in constant interaction not only with each other, but also with the surrounding reality.

Keywords: algorithmic models, productive grammar, systematic language, compatibility of language units in speech.

\section{References}

Aleksandrova Z.E. Slovar' sinonimov russkogo yazyka. Prakticheskij spravochnik. [Dictionary of synonyms of the Russian language. A practical guide]. Izd. 11-e, pererab. i dop. Moscow, «Russkij yazyk/Russian language» Publ., 2001. 568 p. (In Russ.)

Apresyan V. Yu., Pekelis O.E. Sochinitel'nye soyuzy. Materialy dlya proekta korpusnogo opisaniya russkoi grammatiki [Composition unions. Materials for the project of corpus description of Russian grammar] (http://rusgram.ru). Na pravakh rukopisi. Moscow, 2012 URL: http://test.rusgram.ru//Сочинительные_союзы (accessed 02.10.2019). (In Russ.)

Glazunova O.I. Grammatika russkogo yazyka v uprazhneniyakh i kommentariyakh [Russian Grammar in Exercises and Comments]. V 2 ch. Ch. 1. Morfologiya [Morphology]. 9-oe izd. St. Petersburg, «Zlatoust» Publ., 2017a. 424 p. (In Russ.)

Glazunova O.I. Grammatika russkogo yazyka v uprazhneniyakh i kommentariyakh [Russian Grammar in Exercises and Comments]. V 2 ch. Ch. 2. Sintaksis [Syntax]. 5-oe izd. St. Petersburg, «Zlatoust» Publ., 2017b. 416 p. (In Russ.)

Iordanskaya L.N., Mel'chuk I. A. K semantike russkih prichinnyh predlogov (IZ-ZA lyubvi OT lyubvi IZ lyubvi *S lyubvi PO lyubvi) [On the semantics of Russian causal prepositions (IZ-ZA lyubvi OT lyubvi IZ lyubvi *S lyubvi PO lyubvi)] // Moskovskij lingvisticheskij zhurnal. Tom 2/Vol.2. M.: RGGU/Russian State University for the Humanities Publ., 1996, pp. 162-211. (In Russ.)

Kleene S.C. Mathematical Logic. John Wiley and Sons, Inc., New York, London, Sydney, 1967. 398 p. (Russ. ed.: Klini S. K. Matematicheskaya logika / per. s angl. Yu .A. Gasteva, pod red. G. E. Mintsa. Moscow, «Mir/World» Publ., 1973. 480 p.).

Krejdlin G.E., Paducheva E. V. Znachenie $i$ sintaksicheskie svojstva soyuza a [Meaning and synthetic properties of the union $a$ ] // Nauchno-tekhnicheskaya informaciya [Scientific and technical information]. Seriya 2. Informacionnye processy i sistemy [Information Processes and Systems]. 1974, no. 9, pp. 31-37. (In Russ.)

Ozhegov S. I., Shvedova N. YU. Tolkovyj slovar' russkogo yazyka [Explanatory dictionary of the Russian language]. Izd. 4-oe, dop. Moscow, «Azbukovnik» Publ., 1999. 944 p. (In Russ.) 
Paducheva E. V. Egocentricheskaya semantika soyuzov A i NO [Egocentric semantics of the unions A and NO]. Slavyanskie sochinitel'nye soyuzy [Slavic compositional unions]. Moscow, 1997, pp. 36-45. (In Russ.)

Sannikov V.Z. Russkie sochinitel'nye konstrukcii: semantika, pragmatika, sintaksis [Russian compositional constructions: semantics, pragmatics, syntax]. Moscow, «Nauka/ Science» Publ., 1989. 266 p. (In Russ.)

Tolkovyj slovar' russkih glagolov: Ideograficheskoe opisanie. Anglijskie ekvivalenty. Sinonimy. Antonimy [Explanatory dictionary of Russian verbs: Ideographic description. English equivalent. Synonyms. Antonyms] / pod red. L. G. Babenko. Moscow, «ASTPRESS KNIGA» Publ., 1999. 698 p. (In Russ.)

Uryson E. V. Soyuzy a i no i figura govoryashchego [Russian unions $a$ and no, and the figure of the speaker]. Voprosy jazykoznanija, 2004, no. 6, pp. 64-83. (In Russ.)

Uryson E. V. Soyuz no, ili chto takoe «obmanutoe ozhidanie» [Russian unions $a$ and но, or what is «misguided expectations»] // Komp'yuternaya lingvistika i intellektual'nye tekhnologii. Po materialam ezhegodnoj Mezhdunarodnoj konferencii «Dialog» [Computational linguistics and intellectual technologies. Proceedings of the annual International conference «Dialogue»]. Moscow, «Nauka / Science» Publ., 2005. (In Russ.) Available at: http://www.dialog-21.ru/media/2430/urysone.pdf (accessed 02.10.2019).

Vinogradov V.V. Russkij yazyk (Grammaticheskoe uchenie o slove) [Russian language (Grammatical doctrine of the word)] / pod red. G. A. Zolotovoj. Izd. 4-oe. Moscow, «Russkij yazyk / Russian language» Publ., 2001. 720 p. (In Russ.)

Vsevolodova M.V. Funkcional'naya prikladnaya grammatika russkogo yazyka kak osnova dlya sozdaniya uchebnikov i uchebnyh posobij po russkomu yazyku kak inostrannomu [Functional Russian applied grammar as a basis for the creation of textbooks and manuals on Russian as a foreign language]. Sopostavitel'naya filologiya i polilingvizm: Sbornik nauchny trudov [Comparative Philology and multilingualism: Collection of scientific works] / pod red. A. A. Aminovoj, N. A. Andramonovoj. Kazan', 2003, pp. 59-66. (In Russ.)

Wierzbicka A. Semantics, Culture, and Cognition. Universal Human Concepts in Culture-Specific Configurations. N. Y., Oxford: Oxford Univ. Press, 1992. 328 p.

Zaliznyak Anna A., Mikaelyan I. Russkij soyuz a kak lingvospecifichnoe slovo [Russian union $a$ as a specific linguistic word] // Komp'yuternaya lingvistika i intellektual'nye tekhnologii [Computational Linguistics and Intellectual Technologies. Po materialam ezhegodnoj Mezhdunarodnoj konferencii «Dialog» [Computational linguistics and intellectual technologies. Proceedings of the annual International conference «Dialogue»]. Moscow, «Nauka/Sience» Publ., 2005. (In Russ.) Available at: http://www.dialog-21.ru/ media/2439/zalizniak_mikaelian.pdf (accessed 02.10.2019). 